\title{
Ensuring the Teacher Education Students’ Knowledge through the Role Situations
}

\author{
N.N. Kondrashov* \\ Department of Pedagogy, National University named after Bogdan Khmelnitsky, Cherkasy, Ukraine \\ *Corresponding author: kondrashovmm@mail.ru
}

Received September 29, 2013; Revised October 12, 2013; Accepted November 15, 2013

\begin{abstract}
In this article students' success, their problems in the process of learning pedagogical knowledge, reasons of the low results, increasing of quality of knowledge with the help of role - situations at the pedagogical lessons are considered. There are different approaches to define the quality of future teachers' pedagogical knowledge in scientific literature. During the investigation significant differences were found in the quality of the implementation of all functions of the educational process, especially about the characteristic of wording and definition of problems, planning of their decisions. We found out that the effectiveness of educational work in teaching disciplines is mainly determined by the students' attitude to the pedagogical theory and realization of its importance in their future practice. The results of the establish experiment allow us to speak about the necessity to improve the quality of future teachers' pedagogical knowledge in the system of university education. One of the ways to modernize this preparation is the simulation of role-playing situations during teaching of pedagogical disciplines. These methods create conditions for the active cognitive activity, nonstandard solution of pedagogical problems, improve the quality of pedagogical knowledge and the level of readiness for future professional activity.
\end{abstract}

Keywords: pedagogical knowledge, quality estimation of knowledge, role - situation

Cite This Article: N.N. Kondrashov, "Ensuring the Teacher Education Students' Knowledge through the Role Situations.” American Journal of Educational Research 1, no. 11 (2013): 548-554. doi: 10.12691/education$1-11-16$.

\section{Introduction}

Joining of Ukraine to the European education field shows the contradictions in the system of universal education, between aim of creative teacher's formation and means of reaching this aim, between tasks of professional development and ways of its formation, between character of pedagogical formation and personal creative character of pedagogical activity. Withdrawal of these contradictions is defined by the strategy of further improvement of the quality of future teachers' pedagogical knowledge in the system of university education.

\section{Last Researches}

Pedagogical bases of future teachers' preparation were found in works of the following authors: A. Abdylina, U. Babanskiy, L. Kondrashova, N.Kyzminskiy, O.Moroza, V.Slastenina. This problem was theoretically proved and practically realized, but at the same time we must admit that content - procedure way was undervalued in the process of quality increasing of pedagogical knowledge in the system of university education.

It is noted in the national doctrine of Ukraine education and in the law "About higher education" that the existing system of education does not completely corresponds to the changing needs of society and innovation activity in all its spheres. Today it is obvious for us that we need qualitative modernization of the entire education system, including higher pedagogical education.

\section{Methodology}

However, in our opinion, it is not focused attention to the improvement of mechanisms of pedagogical preparation and improvement of the quality of future teachers' pedagogical knowledge. The quality of the pedagogical knowledge and the process of assimilation are associated with pedagogical innovations, introduction of new idea in teaching practice. Innovation is understood as a purposeful change in any system, in result of which it passes from one state to another. But the results from innovations can have the positive affect on the quality of mastering of educational knowledge and can be ineffective. Unfortunately, the introduction of pedagogical ideas and methodological developments do not always have a positive impact on the quality of students' knowledge. Observation, analysis of an university practice allows us to speak about the necessity of modernization of the system of university education with the purpose of increasing its quality.

\subsection{Objectives of the Study}


The aim of the research is to identify and theoretical substantiate the reasons of the low quality of students' pedagogical knowledge in the system of university education and the use of role-playing situations during studying of pedagogical subjects as a means of increasing of the effectiveness of the educational process.

\section{The Quality of Studying Pedagogical Disciplines}

There are different approaches to define the quality of future teachers' pedagogical knowledge in scientific literature. The parameters of quality are: the ability to see the problems; sensitiveness to the opportunities of the development; the ability to use the available opportunities for the improvement of the education system; creativity as a way of creating innovations that stimulate the quality of pedagogical activity.

\subsection{Quality Assessment of Studying}

Taking into consideration these merits, we assessed the quality of studying of pedagogical disciplines on the basis of modeling of role-playing situations (Qpk). The quality of studying of pedagogical disciplines was defined as the ratio of the potential future teachers' opportunities and their actual professional promotion during the educational process based on the simulation of role-playing situations. We interpret the integral assessment of the quality (Qpk) as a function of the implementation of the educational tasks by the student in the process of mastering of the system of pedagogical knowledge and experience of pedagogical activity:

a. Analysis of the level of students ' knowledge and the identification of the relevant issues, taking into account the contemporary demands of society towards the pedagogical professionalism (problematization).

b. Search of non-standard solutions.

c. Planning of organization of mastering of pedagogical knowledge - assessment of quality.

d. Participants' motivation of educational process.

e. Students' educational achievements in the studying of educational theory-based on the modeling of the role playing situation.

f. Monitoring, regulation of the course of studying of pedagogical theory and assessment of the results.

On the bases of these characteristics we defined that:

$$
\mathrm{Q}(\mathrm{pk})=\mathrm{f}\left(\mathrm{Q}_{\mathrm{pr}}, \mathrm{Q}_{\mathrm{ud}}, \mathrm{Q}_{\mathrm{pl}}, \mathrm{Q}_{\mathrm{mot}} \text {, Qea, Qmon }\right) \text {, }
$$

Where:

$\mathrm{Q}(\mathrm{pr})$ - the evaluation of the quality of the wording and problems;

Q(ud) . quality assessment of unusual ways of solving problems;

$\mathrm{Q}(\mathrm{pl})$ - evaluation of the quality of educational planning and its implementation;

$\mathrm{Q}$ (mot) - assessment of the motivation and students' active work;

$\mathrm{Q}(\mathrm{ea})$ - assessment of the quality of educational achievements;

$\mathrm{Q}(\mathrm{mon})$ - monitoring and evaluation results.

The quality of the problematization of the educational process is characteristic of pedagogical activity based on modeling of the role - playing situation and ability to identify the current problems, tasks of its optimization and adequately estimation of their significance in the modernization of the process of studying of pedagogical disciplines.

Evaluation of the quality of non-standard ways of solving problems and identification of their opportunities in the modernization of the process of mastering of pedagogical knowledge, its aims, content, principles, forms, methods and means. An adequate evaluation of their use in practice.

Quality of planning involves the organization of studying of pedagogical subjects, aims, content, methods and technologies, correspondence of their opportunities with their real conditions and the development of a system of pedagogical activities ensuring the effectiveness of the educational process, the achievement of aims through simulation of role-playing situations in the classroom.

The quality of motivation is a characteristic of the incentives that stimulate to active actions and productive work on mastering of pedagogical knowledge and experience of pedagogical activity.

The quality of students' educational achievements is a characteristic of correspondence of expected results and the real level of their professional development, through simulation of role-playing situations in the process of mastering of pedagogical knowledge.

\subsection{The Reasons of Problem Situation}

During the investigation significant differences were found in the quality of the implementation of all functions of the educational process, especially about the characteristic of wording and definition of problems, planning of their decisions.

Indicators of the quality of the mastering of the content of pedagogical disciplines with integral evaluation of educational achievements below and above of the average level. In the course of establish experiment we identified $20 \%$ of students with the quality of pedagogical knowledge that is above average, with quality below the average is $64 \%$ of student. However, teachers and students assess the quality level of mastering of educational theory inadequately.

It is necessary to look for the reasons of this situation in its underestimate as an important component of the students' professionalism in the system of university education, outdated content, methods and technologies, the prevalence of reproductive forms and methods in studying of pedagogical disciplines, ignoring of the creative nature of the teaching work and its specificity in the educational process.

\subsection{Data Analysis}

The information collected during the students' opinion poll argues about the unused reserves of the educational process in improving of the quality of students' pedagogical knowledge. We asked the question: «How do you rate the quality of the educational process in the University?». Answers were received: $18 \%$ of students are satisfied with its quality; $32 \%$ of students estimated it as qualitative than poor; $36 \%$ of students considered its positive achievements and shortcomings; $7 \%$ of students 
consider that it is low-quality process; $7 \%$ of students think that it is useless work, a waste of time.

The analysis of attended classes in teaching disciplines shows that the reasons of the decline of quality of pedagogical knowledge are based on:

1. The decreasing of the prestige of the teaching profession in the students' eyes (only 35\% of students would have repeated their professional choice, if they had had the possibility of a new choice);

2. The lack of positive motivation in the process of studying of pedagogical subjects (39\% of students learn pedagogical disciplines in order to fulfill the curriculum);

3. Teachers' underestimation of innovative technologies (41\% of teachers answered that they used innovation in their practice; $25 \%$ of teachers use traditional technologies, approved by time and practice; $34 \%$ of students believe that the 'new' - is well forgotten old);

4. Imitation of activity by teachers, but real absence of changes in their work (often - 27\%, not often, but not rarely-51\%);

5. Underestimation of active forms and methods, preference for verbal and reproductive methods and traditional forms (often - 27\%, but not rarely - 29\%).

The analysis of the students' educational achievements in the process of capture of pedagogical knowledge and experience of pedagogical activity allows us to speak about low efficiency of the educational process in the system of university education. The analysis of examination marks in pedagogical disciplines indicates about overstating of results of academic work. $79 \%$ of respondents noted, that the teachers estimate knowledge formally.

In the course of establish experiment we found out that a majority of students are not satisfied with the level of teaching of pedagogical disciplines, formalism in the actions of the teachers. There is a stable dynamics of unsatisfied students with quality of teaching of pedagogical disciplines. Are you satisfied with the organization of educational process in pedagogical disciplines? 169 students answered «Yes»; 109 - «not at all»; 22 - «no»; and organization of pedagogical practice 149 students answered «Yes»; 136 - «not at all»; 15 «no». The level of teaching satisfies - 163 students; 110 - «not at all»; 27 - no.

Students' academic achievements show a low quality of the pedagogical training. A total sample of students' educational achievements showed the following results: excellent result - only 44 people; good - 136 people; «satisfactory» - 120 people. Every third student has satisfactory knowledge. The reason of "satisfactory» students' successes is no coincidence of the professionalpedagogical motivation and the character of their educational activity.

\subsection{The Students' Attitude to the Pedagogical Theory}

The effectiveness of educational work in teaching disciplines is mainly determined by the students' attitude to the pedagogical theory and realization of its importance in their future practice. With the help of Rokich's test we learned the students' attitude to creative assimilation of pedagogical knowledge. Students gave their preference to such characteristics as creativity (the first place) and independence (the second place). Of the possible 16 seats cognitive activity is on the 11th place, and creativity in knowledge is the 12th place. Formalism and dogmatism in the organization of educational process in pedagogical disciplines, mechanical mastering of educational theory, and underestimation of role-playing methods in teaching are the reasons of misprision of creative cognitive activity. Students' preference of such qualities-values (creativity and independence) suggests that they often are passive, act as a simple performers of instructions and methodical recommendations and teachers' instructions. Formalism in the teachers' actions and ignoring of creative kinds of educational activities have a negative impact on the formation of positive attitude to the study of pedagogical disciplines.

The results of methods of incomplete sentences prove the low level of positive motivation of learning pedagogical disciplines. So, the sentence «In the teaching of pedagogical subjects I am interested in...» only $10 \%$ of students chose the cognitive interest and $30 \%$ of students could not perform a task. The sentence «I am interested in such teaching process, as.. » $48 \%$ of students kept silence, $24 \%$ of students showed interest in active forms and methods of organization of educational process and this adjusts with their desire to values as independence of judgment, dialogical interaction, activity and creativity of educational action.

The choice of three types of training: «an interesting presentation of the educational information by the teacher, the combination of active actions in the system of relations «teacher - student», an independent study of pedagogical information» showed that students are not enough motivated for independent work. The last variant of the training was not chosen by any student. 27\% of students did not make a choice about these three variants. $43 \%$ of students preferred passive studying of pedagogical disciplines under the teacher's leadership. 30\% of students noted the necessity of interaction with teachers and independent work in the educational process.

During the experiment we committed the presence of students' cognitive interest to pedagogical literature. Found results with the help of interview, expert assessments and survey showed that only $17 \%$ of students show interest in pedagogical literature. More than half $53 \%$ of students have situational interest, often they remain indifferent to the pedagogical information and use it only when it is absolutely necessary. $27 \%$ of students have no interest in pedagogical literature. They have very low interest and in pedagogical experience (30\%). The reasons of this situation should be searched in the students' low orientation on the practical importance of pedagogical knowledge and their role in the increasing of the effectiveness of the teaching work.

\subsection{The Analyze of Collected Facts}

The analyze of the collected facts allows us to speak about a systematic underestimation of the work connected with the disclosure of the practical importance of pedagogical theory in the preparation of creative teachers, the formation of his active professional position, the development of the necessity to have pedagogical innovations. For example, $63 \%$ of students do not see the relation of pedagogical theory with the growth of the level 
of their professionalism; only $12 \%$ of students associate pedagogical awareness with the teacher's success.

Many students have a low level of readiness for selfeducation and skills to acquire necessary information and use it for the solving of educational problems. 56\% of students explain these gaps for lack of time and inability to work independently. $44 \%$ of students explain failure in academic work because of unwillingness to study pedagogical disciplines, fatigue, bad memory, irresponsible attitude to the teaching.

Low effectiveness of the training achievements is explained by the lack of students' motivation oriented on mastering of professional-pedagogical activity. They do not want to be in sphere of teaching after graduation from university. Motivation of students' educational activity is characterized by pragmatism. Personal, creative motivation is weak, and this fact significantly reduces the interest in learning of pedagogic disciplines and negatively affects on the quality of pedagogical knowledge of future teachers.

Taking into consideration that communication skills play important role in the pedagogical activities, we studied the students' ability to communicate. The aim of test was to establish the level of students' readiness for communicative work before the beginning of the experiment. During the establish experiment we detected culture of the students' communication, ability to use previously mastered knowledge, culture and emotion of speech, the effectiveness of implementation of the proposed roles. With the help of questionnaires, we found out that $43 \%$ of the students are not able to create the necessary atmosphere for communication; $57 \%$ of the students are sure that they have a barrier to communication. Most of them can not express their attitude to what is happening in simulated pedagogical situations that reflect educational reality; they have no clear idea about the strategy and tactics of communication.

\section{Students' Pedagogical Competence}

The analysis of the attended classes shows that traditional forms and methods of cognitive activity are used. In this process the main task is to give the information and the procedural side is out of attention. The role of student is a passive listener. This situation explains why students have dominated formal knowledge and can not use theory in the solving of practical problems.

During the establish experiment we examined the extent of students' pedagogical competence as one of the characteristics of their professionalism with the help of the method of modeling of problem situations. Students were offered to find a way out from the situation that contains events from the pedagogical activity.

They were asked to use pedagogical concepts and methods that reflect the experience of pedagogical activity; to transfer earlier mastered technologies in new situations; to build the models and evaluate their adequacy. The imitation of professional situations in the educational process and their totality got the name of the case [1]. The difficulty of this method consists in the selection of the situational tasks of pedagogical direction and ensuring of the reliability and comparability of measurement results.

Therefore, role-playing situations were used as means of formation of students' pedagogical skills. The aim of it is to determine its level in the process of mastering of educational theory and practice. The situation covered various spheres of educational activities (private conversation with a student, a fragment of the first lesson, dialogue with parents, the analysis of the activities and other). Roles were given according to the wish. The received information shows that $45 \%$ of students do not possess professional skills, they have difficulties in the use of educational theory for the solving problems, 55\% of the students showed low level of communicative competence.

\subsection{Gaps in the Methods of Higher Education}

At the stage of establish experiment significant gaps in the methods of higher education and the nature of the level of pedagogical competence were found out. The reasons that have the negative influence on the quality of students' pedagogical knowledge and the effectiveness of pedagogical activity are: the underestimation of the formation of motivation of pedagogic disciplines and positive attitude to the teaching profession, educational and professional interests, skills of educational work; development of pedagogical thinking, creativity, self determination and necessity in the pedagogical innovation as important indicators of modern teacher's professionalism.

Most of the teachers have difficulties in the solving of didactic tasks: the formation of positive motivation, professional thinking, skills of educational work. Teaching of pedagogical disciplines is notable for formalism, the relations in the system «teacher - student» are based mainly on the pedagogical influence but role of pedagogical interaction, cooperation and co-creation is underestimated.

$64 \%$ of teachers do not focus on learning students' possibilities and abilities, explaining the lack of lack of time, $36 \%$ of teachers have no necessary methodical literature; $63 \%$ of teachers think that student must learn if he came to the higher school.

The analysis of results of studying of pedagogical disciplines by the students allows us to speak about the low quality of their pedagogical knowledge. The given facts show significant gap in mastering of the basics of psychological-pedagogical diagnostics by students and teachers, using of diagnostic tools (questionnaires, observation, interviews, tests, analysis of the results of student activities) and their means of an objective assessment of the level of pedagogical competence as one of the indicators of pedagogical excellence.

\section{Role-Playing Situations}

During the study we found that the pedagogical competence has practical orientation and manifests itself through the prism of personal characteristics only in the process of activity. The performance of different types of work allows to evaluate the formation of this complex personal students' quality. According to M. Shalashov, "correlation of the content of the practices with the role functions in other activities can reduce the gap between" academism" of education and practical training of a graduate [3].

Competences are formed due to the content of education, learning environment and technologies based 
on the principles of role-playing activities. Pedagogical competence is formed due to the studying of the pedagogical disciplines in the process of modeling of roleplaying situations, professional orientation.

Role-playing situation as a process of reflection of real activity serves as a means of search by the students the decision of pedagogical problems, transfer of knowledge in new conditions, the conversion methods of the activity and performance of necessary professional procedures to ensure the quality of pedagogical knowledge and acquisition of the experience of creative action.

Role-playing perspective allows to represent the pedagogical theory as a whole system of pedagogical facts, phenomena and ways of mental recreation of pedagogical process. Pedagogical information is not simply a set of theoretical facts, but also it is the process of feeling by a student of certain emotional state. Role-playing situation is a special method of the simulation of pedagogical event or process in the individual consciousness and the reconstruction of individual experience.

Role-playing situation stimulates the manifestation of professional information and educational roles when values and actions have practical importance for each student. Knowledge-values is the basis of personal-andsemantic relations that ensures the movement from the active consciousness to professional behavior of the individual.

Personal-semantic relationships are characterized by:

a. presence of student's active position as a subject of pedagogical activity;

b. positive motivation that means the active role of the actions;

c. humanistic relations in the system «teacher students», based on the pedagogical interaction, cooperation and collaboration;

d. transfer of knowledge in the personal sense, professional values;

e. active actions that have professional installations.

All this gives grounds for the selection of targets, the variety of roles that are used by the student as an instrument for the development of his professional conduct.

The modeling of role-playing situations in the educational process involves the students' work with the theoretical model. The student is in pedagogical event, but at the same time he must be out of it and accept pedagogical event as a subject with which he can make mental experiment. Co - operation in the role- playing situation is achieved with the help of unity of knowledge and practical actions.

In the role- playing situation pedagogical information is presented at the level of knowledge, feelings and actions. This harmony provides he improving of the quality of students' knowledge and mastering of the procedure of the theoretical analysis and evaluation of pedagogical facts and processes.

\subsection{Main Features of Role-Playing Situations}

A characteristic feature of the role - playing situation is the organization and presentation of the materials on the basis of positive emotions. They ensure students' necessities in cognitive activity. The domination of positive emotions and motivation during teaching of pedagogical disciplines stimulates interest and provides a qualitative studying of educational theory. In the process of acting roles and participation in various forms of organization of the educational process we have conditions for many facts that give practical orientation of the pedagogical knowledge. Such lessons contain great opportunities for a variety of role-playing situations and repetition of their different options. The absorption of pedagogical information is carried out in the context of professional activities, when knowledge conducts means of its realization, and forms of organization of educational process are as ways of activity of an acquired contents of pedagogical disciplines.

\subsection{Kinds of Seminars}

In our experiment different kinds of seminars were used. They are represented in the Table 1.

Table 1. Kinds of seminars

\begin{tabular}{|c|c|c|}
\hline № & Kinds of seminars & Aim and task \\
\hline 1. & Seminar-discussion & $\begin{array}{c}\text { The aim is to improve students' knowledge and create pedagogical thinking. In this situation the skills } \\
\text { are practiced, experience of activity in extraordinary situations is fixed }\end{array}$ \\
\hline 2. & $\begin{array}{l}\text { Seminars with reports and } \\
\text { abstract }\end{array}$ & $\begin{array}{l}\text { Its aim - to improve the pedagogical knowledge, assess the capabilities and the level of readiness to } \\
\text { work with the various sources of information, the ability to analyze, evaluate the degree of elaboration } \\
\text { of pedagogical problems in the scientific literature }\end{array}$ \\
\hline 3. & Seminar -debate & $\begin{array}{l}\text { With the help of different approaches and points of view students learn to solve non-standard } \\
\text { problems, generate professional-pedagogical outlook, improve pedagogical tact and culture of } \\
\text { communication }\end{array}$ \\
\hline 4. & Seminar -discussion & $\begin{array}{l}\text { Come students to the correct understanding after listening to all opinions about the problem, show the } \\
\text { creative nature of the material, so that students can see the dynamics of educational thought, identify } \\
\text { perspective and ways of solving questions about teaching practice }\end{array}$ \\
\hline 5. & Seminar-dialogue & $\begin{array}{c}\text { Development of the dialogic interaction and communication skills, improving of communicative and } \\
\text { creative abilities, the use of various means of communication and intensification of private thinking } \\
\text { and original idea }\end{array}$ \\
\hline 6. & Seminar-conference & $\begin{array}{l}\text { Forming of the conditions for creative learning activities, full understanding of pedagogical theory. } \\
\text { Mastering of the skills to analyze academic work, the involvement of students in the discussion of } \\
\text { current educational problems and needs of teaching practice. }\end{array}$ \\
\hline 7. & Seminar - business game & $\begin{array}{l}\text { Show the practice-oriented focus of educational theory, to form the ability to use theoretical concepts } \\
\text { to explain the pedagogical actions and decisions, to create the conditions for self-expression, self- } \\
\text { determination of future teachers, the development of individual style and an active professional } \\
\text { position }\end{array}$ \\
\hline 8. & Workshop & $\begin{array}{l}\text { Check knowledge of educational theory, to identify the formation of communicative, constructive and } \\
\text { Gnostic skills, the ability to propose creative solutions of pedagogical problems. }\end{array}$ \\
\hline
\end{tabular}




\section{The Structure of an Experienced Lesson}

The module-block approach with the using of roleplaying situations is in the bases of the structure for the course "Pedagogy". Here is the structure of an experienced lesson.

Theme: The logic and methodology of educational researches.

Aim: reveal the logic of pedagogical research, help future teachers in mastering of the technique of scientific and pedagogical research.

The structure of the lesson:

\section{Information and discussion unit}

Questions for discussions:

1. What should be considered during the research of pedagogical topic and the selection of teaching methods for solving scientific problems?

2. Definitions of what concepts are given below:

- associated with the establishment of the basic laws of pedagogical regularities as the assumptions of scientific research that includes an ideological function, i.e. a function that determines what philosophical, biological and psychological ideas are used in the process of pedagogical research. The given results are explained and conclusions are made.

- the formation of new pedagogical knowledge; kind of cognitive activity aimed to discover the objective laws of learning, training and development.

- study of the general principles of the approach to the educational facilities, the study of the system of general and specific methods and techniques of scientific pedagogical research.

- a system of knowledge about the starting positions of educational theory, principles of approach to the consideration of pedagogical phenomena and methods of their research, ways of introductions of knowledge in the practice of education, training and education.

3. Find a discrepancy between definitions and concepts:

Tasks of research - concise and clear restriction of the aspects of the study area.

Hypothesis of research - sphere of search.

Topic of research - the limited aspect of the sphere of the search within the facility, the processes of the realization of the studying phenomena, a set of elements, relationship.

The problem of research - question that appears and requires the answer; this is the statement of what is unknown in the studying.

The aim of research - identification of causal relationships and patterns, the development of theories and methods.

Subject of research- specification of the aims of research; define, identify and check in the experimental work.

Object of research - offered answer to question, developed on the basis of a comprehensive study of the theoretical and practical condition of the problem.

II. Practice - transformative unit.

4. Define how correctly methodological instrument of investigated topic is formulated:

Teacher's creative approach to the structuring of the lesson
Object of research: lesson and its forms.

Subject of research: tasks of the lesson that correspond to its creative character.

Hhypothesis: creativity, specially during the lesson, must have the bases (cultural, emotional and intelligent).

Methods of research: the analysis of the literature about the problem of the lesson, digital method, development of the series of lessons

5. Analyze the situation:

A new director came in teaching staff. He has done a number of changes: change the system of management (it became more flexible and adapted to the conditions of the school), introduced a new system of distribution of responsibilities between teachers, focused efforts on the creative basis of the organization of teaching activities, introduced new means of teacher encouragement, clearly defined aims and tasks of the teaching staff.

What pedagogical effect can be expected from these innovations? What is your attitude towards the director's actions? What would you change if you were the director?

\section{Reflective unit}

1. What is the methodological basis for the educational research?

2. The logic of pedagogical research. How do you understand this concept? Name the main stages of pedagogical research..

3. What determines the choice of research methods?

4. Methods and technology of research. What is their similarity and difference?

5. Research activities - the creative process. How can researcher show his creativity?

\section{Unit of free exchange of information}

1. What do you think? Is it possible to improve the results of educational activity with the help of the methodology of pedagogical research?

2. During the lesson the topics of research have been formed. What nominations are you interested in? Explain why.

3. If you uphold some idea, you:

A. can give it up if you listen to opponent's persuasive idea;

B. you stuck your own opinion no matter what arguments are given;

C. change your mind if opponent is too strong in his position;

4. What do you like and dislike during the lesson?

5. Your prepositions about improving of lesson results.

V. Unit of self - education

The results of experimental studies have shown us an increasing of the quality of students' knowledge of the experimental group in comparison with the students of the control group who were trained with the traditional method (sufficient level of knowledge of students was $48.9 \%$ against $27.2 \%$, the highest level - $14.8 \%$ against $8.7 \%$ at the beginning of the experiment).

Positive changes of the quality of knowledge allow us to claim that focusing on the role-playing situation (with the aim to activate the internal reasons) greatly increases the students' interest in learning activities, their needs in pedagogical knowledge and further application in practical situations.

In the process of various forms (games, dialogue, academic discussions, debates, role-based plan) students have the opportunity to express their point of view about 
the solution of a pedagogical problem, reveal his professional position, show creative abilities and a certain level of creative thinking.

Role-playing situation allows students to direct their attention to pedagogical situations and easily choose the ways of actions oriented on achievement of predictable results.

Role-playing situation provides the opportunity for searching of the decision of new tasks associated with the failure of pedagogical knowledge and the absence of the algorithm for solving the proposed situations.

Role-playing situation suggests an innovative restructuring of the evaluation of the quality of mastered pedagogical knowledge, skills and abilities of students, as it estimates their ability to orient on integrated, interdisciplinary knowledge, ability to own analysis and synthesis, the transferring of knowledge on new situations, generating of new ideas and creative action.

Objective estimation of quality of students' knowledge, timely identification of the nature of learning motivation, attitude to the chosen profession, readiness for action in pedagogical situations stimulates the growth of the level of pedagogical competence in a positive direction.

\section{Conclusion and Recommendation}

Higher education is «mechanism of translation of values, norms, ideals and senses of life, a means of reproduction of a specific «national peace» distinguishing this cultural system from all the others» [2]. The whole system of University education is oriented on mastering of fundamental knowledge of education disciplines and training of future specialists to use them creatively for solving professional problems.

The results of the establish experiment allow us to speak about the necessity to improve the quality of future teachers' pedagogical knowledge in the system of university education. One of the ways to modernize this preparation is the simulation of role-playing situations during teaching of pedagogical disciplines. Role-playing situation is realized with the help of playing and problemsituational methods of education. These methods create conditions for the active cognitive activity, nonstandard solution of pedagogical problems, improve the quality of pedagogical knowledge and the level of readiness for future professional activity.

\section{References}

[1] Aseyev, V.G, The motivation of behavior and formation of personality, Thought, Moscow, 1976, 158.

[2] Great Encyclopedic Dictionary. Prokhorova A. M, The second, St. Petersburg, 2002, 1102.

[3] Zvonnikov, V. I, Working and certification of classific tests, Moscow, 2007, 127.

[4] Kondrashova, L.V, Theoretical foundations of education of moral -psychological readiness of students of teacher training college to the professional work : Abstract Doctor. dis., Moscow, 1989, 36.

[5] Kondrashova, L.V, Fundamentals of didactics of higher education, Kherson, 2011, 326.

[6] Kravchenko, N.G, "The algorithm of control of situational field during the process of teaching foreign language", Information Technology equipment, №11, 21-25, 1993.

[7] Makarov, A. P, "The crises of identity and resources of humanitarian education", Pedagogy, №7, 12-17, 2001.

[8] Professional career of a young teacher, Vershlovsky, S. G, Lesokhina, L. I, etc., Moscow, 1982, 144.

[9] Shalashov, M. M, "The complex estimation of future teachers' competence", Pedagogy, №7, 54-56, 2088. 